\title{
Heterozygosity and developmental stability in gynogenetic diploid and triploid rainbow trout
}

\author{
Robb F. Leary, Fred W. Allendorf, \\ Kathy L. Knudsen and \\ Gary H. Thorgaard'
}

Department of Zoology, University of Montana, Missoula, Montana 59812;

${ }^{1}$ Program in Genetics and Cell Biology, and

Department of Zoology, Washington State University,

Pullman, Washington 99164-4350, USA.

We have previously reported that rainbow trout (Salmo gairdneri) more heterozygous at enzyme loci generally show increased developmental stability, as measured by reduced fluctuating asymmetry. We experimentally produced gynogenetic diploid and triploid individuals to test the effect of extreme heterozygosities on developmental stability. Gynogenetic diploids are identical by descent at an estimated 34 per cent of all loci and show a 50 per cent increase in the mean proportion of traits asymmetric per individual compared to normal rainbow trout. Triploids from two different strains have an estimated 30 per cent increase in genomic heterozygosity and a 14 per cent decrease in the mean proportion of traits asymmetric per individual compared to normal diploids. These changes in asymmetry induced by gynogenesis and triploidy are not as great as we expected based on the association between heterozygosity and fluctuating asymmetry in random mating populations. The narrow range of mean asymmetry in rainbow trout may result from an upper limit restricted by directional selection for developmental stability and a lower limit determined by inherent randomness in the developmental process.

\section{INTRODUCTION}

Waddington $(1942,1948)$ was among the first to stress the evolutionary importance of the genetic control of the developmental process. He proposed that natural selection acts to produce developmental pathways that are insensitive to changes in the environment or the genome so that the phenotypic norm of the species is preserved (Waddington, 1942). He referred to this as the buffering or canalisation of development. Lerner (1954) subsequently proposed that heterozygosity stabilises development so that genetically determined developmental pathways are more precisely expressed in the phenotype of individuals. Thus, more heterozygous individuals are more developmentally buffered and are more likely to express the characteristic morphology of the species.

Individuals more heterozygous at 42 enzyme loci in populations of rainbow trout (Salmo gairdneri) show increased developmental stability, as measured by reduced fluctuating asymmetry for five bilateral meristic characters (Leary et al., 1983, $1984 a$ ). Fluctuating asymmetry occurs when the difference between a character on the left and right sides of individuals in a population is normally distributed with a mean of zero (Van Valen, 1962) and reflects the inability of an individual to develop precisely along genetically determined pathways. It is surprising that such a phenotypic effect of heterozygosity can be detected by the relatively small number of loci that are amenable to electrophoretic analysis (Chakraborty, 1981). For example, individual heterozygosity in our samples ranges from zero to six heterozygous loci. Nevertheless, we have consistently detected a negative correlation between heterozygosity and fluctuating asymmetry in populations of rainbow trout and other salmonid fishes. We have also found significant negative correlations in three generations of fish from the Arlee strain of rainbow trout raised in different environments (Leary et al., $1984 a, 1985 a$ ).

The chromosome sets of salmonid fishes can be manipulated experimentally (Thorgaard, 1983). This presents the opportunity to examine the relationship between heterozygosity and developmental stability for ranges of heterozygosity not 
normally present in random mating populations. For example, a pressure or temperature shock shortly after activation of eggs by genetically inert spermatozoa induces diploidy through the retention of the chromosome set destined to become the second polar body (Purdom, 1983). The heterozygosity of such gynogenetic diploid individuals depends upon the rate of second meiotic division segregation, $y$ (Allendorf and Leary, 1984). The mean value of $y$ estimated from 14 loci in gynogenetic diploid rainbow trout is 0.66 (Thorgaard et al., 1983; Guyomard, 1984). This is equivalent to an inbreeding coefficient of $0 \cdot 34$. A pressure or temperature shock shortly after activation of eggs with functional sperm is an effective method of producing triploid individuals containing two maternal chromosome sets. We expect triploid rainbow trout to have approximately a 33 per cent increase in genomic heterozygosity (Allendorf and Leary, 1984).

In this paper, we compare the developmental stability of gynogenetic diploid and triploid individuals to that of normal rainbow trout by an examination of fluctuating asymmetry at five bilateral meristic traits. Our results indicate that gynogenetic diploids have increased fluctuating asymmetry and generally have lower meristic counts than normal diploids. This and previous results (Leary et al., 1985b) suggest that the increase in asymmetry is related to the inability to produce the genetically programmed number of body parts. In contrast, triploids have decreased fluctuating asymmetry and similar meristic counts compared to their normal diploid counterparts.

\section{METHODS}

Electrophoretic procedures and nomenclature for the 42 isozyme loci examined are described in Leary et al., (1984a). Karyotypic procedures are described in Thorgaard et al., (1981).

Techniques for producing gynogenetic diploids are described in detail by Thorgaard et al., (1983). We used the Arlee strain of rainbow trout maintained by the Montana Department of Fish, Wildlife and Parks in the gynogenetic diploid experiments. A ten minute heat shock $\left(28^{\circ}-29^{\circ} \mathrm{C}\right)$ ten minutes after activation of eggs by sperm treated with ultraviolet light was used to induce retention of the second polar body. Gynogenetic diploid families were raised at the University of Montana.

Triploid lots of fish were produced from the Arlee strain and from the Spokane strain maintained by the Washington State Department of Game as described by Scheerer and Thorgaard (1983). The same heat shock regime was used after fertilisation by untreated sperm. The triploids were raised at the same hatcheries that maintain the parental strains: Jocko River State Trout Hatchery, Arlee, Montana and the Spokane State Trout Hatchery, Spokane, Washington.

We took the counts of five meristic characters on the left and right side of each fish: pectoral fin rays, pelvic fin rays, gillrakers on the upper first branchial arches, gillrakers on the lower first branchial arches, and mandibular pores. These characters can be easily and accurately counted and they are determined early in development so that counts can be compared between fish of different ages (Leary et al., 1984b). Pairwise $F$ and $t$-tests have revealed no significant differences in variances and means of the distributions of these characters between the sexes (Leary et al., 1983), and we have combined the data from the sexes in our analyses. The mode of the differences between the left and right counts of each character is zero, and there are no significant differences between the means and variances on the left and right sides. All the characters, therefore, exhibit fluctuating asymmetry (Van Valen, 1962). We use two measures of developmental stability: (1) the mean number of traits asymmetric per individual and (2) the mean magnitude of asymmetry, which is the sum of the absolute values of the left minus the right counts for all five traits per individual.

\section{RESULTS}

\section{Fluctuating asymmetry}

\section{Gynogenetic diploids}

We examined the effects of inbreeding by gynogenesis on developmental stability in several ways. First, two-thirds of the eggs from three females were activatcd with genetically inert sperm and heat shocked. Each male used was a homozygote for an allozyme not carried by the female for at least one locus so that fertilisation by an active sperm could be detected. One-third of the eggs from these three females were fertilised with active sperm and not subjected to heat shock to produce normal diploids. This male was a homozygote for an allozyme not carried by the female or the male used to produce gynogenetic progeny. Thus all progeny from a female were isozymically distinguishable; this allowed us to raise them together 
to eliminate the effects of different rearing conditions.

We compared the distributions of the number of asymmetric characters and the magnitude of asymmetry between the first 25 normal and gynogenetic individuals identified from each female (families $\mathbf{J} 19, \mathbf{J} 21$, and $\mathbf{J} 23$; table 1 ). Only nine gynogenetic diploids survived to the time when the sample was collected from family J19. The gynogenetic diploids have significantly higher mean values of both measures of fluctuating asymmetry than the normal diploids produced by each female (Wilcoxon two-sample test, $P<0 \cdot 05$ ).

Table 1 Mean asymmetry in gynogenetic diploid and normal diploid families of rainbow trout

\begin{tabular}{lllll}
\hline & \multicolumn{3}{c}{ Gynogenetic } & \multicolumn{2}{c}{ Normal } \\
Family & Number & Magnitude & Number & Magnitude \\
\hline J1 & - & - & 1.76 & 1.92 \\
J2 & - & - & 1.90 & $2 \cdot 13$ \\
J3 & - & - & 1.18 & 1.50 \\
J4 & - & - & 1.49 & 1.66 \\
J5 & - & - & 1.60 & 1.70 \\
J6 & - & - & 1.40 & 1.44 \\
J7 & - & - & 1.46 & 1.58 \\
J8 & - & - & 1.74 & 1.84 \\
J9 & - & - & 1.46 & 1.60 \\
J10 & 2.16 & 2.40 & - & - \\
J11 & 2.56 & 2.97 & - & - \\
J19 & 2.11 & 2.11 & 1.36 & 1.44 \\
J21 & 2.00 & 2.20 & 1.32 & 1.56 \\
J23 & 2.52 & 2.92 & 1.24 & 1.36 \\
Mean & 2.27 & 2.52 & 1.49 & 1.64 \\
\hline
\end{tabular}

We next compared five gynogenetic diploid families with twelve families of normal diploids made at the same time and raised in the same rearing facilities. The families from the previous results are used in these comparisons. Inert spermatozoa used to activate the eggs in the two additional gynogenetic families again came from males that were homozygous for an allozyme not carried by the female to detect any "leakage". All of the gynogenetic families have a higher mean number of asymmetric traits than all of the normal diploid families raised under the same environmental conditions (sign test, $P<0.001$; table 1). Only one normal diploid family had a higher mean magnitude of asymmetry than one gynogenetic family.

Finally, we combined the 9 gynogenetic individuals from $\mathrm{J} 19$ and the first 25 individuals from each of the other gynogenetic diploid $(N=$ 109) and normal $(N=300)$ families into two "population" samples to compare the proportion of individuals asymmetric for each character. A higher proportion of the gynogenetic diploids were asymmetric for each character and this difference is significant (contingency chi-square, $P<0.05$ ) for all characters except for pectoral fin rays. Thus, the increased asymmetry associated with decreased heterozygosity due to gynogenesis appears to be organism-wide affecting all traits.

One family of gynogenetic diploids, J11, experienced an unusually high mortality rate throughout the time that the samples were collected. There was no evidence of disease, and other families raised in other sections of the same tank did not experience similar mortality during this period. The fish that died in this family over a 27 day period had a higher mean number of asymmetric traits per individual $(3 \cdot 00$ vs. $2 \cdot 56, P<0 \cdot 10)$ and a significantly higher mean magnitude of asymmetry $(4.22$ vs. $2.97, P<0.03)$ than those alive at the time of sampling. Furthermore, among the mortalities there is a negative correlation between both measures of fluctuating asymmetry and data of death $(r=-0 \cdot 12, P<0 \cdot 35)$.

\section{Triploids}

Triploid rainbow trout were produced by postfertilisation heat shock at the Arlee and Spokane hatcheries; 54 and 32 pairs of males and females were used respectively. Karyotypic analysis of embryos indicated that 24 out of 25 fish in the Arlee and 33 out of 35 fish in the Spokane lots were triploids. Furthermore, the dosages of electromorphs at $C k 1, G 3 p 1, I d h 2, L d h 4, \operatorname{Pgm} 2$, and Sod 1 were concordant with triploidy for all individuals heterozygous for at least one of these loci in our samples used for meristic analysis ( 44 out of 57 and 45 out of 52 individuals in the Arlee and Spokane samples, respectively). We could not reliably score dosages of electromorphs at the two variable pairs of duplicated loci that share common alleles, Idh 3,4 and Mdh3,4 (see Leary et al., (1983) for a discussion of these loci).

We compared the heterozygosity and fluctuating asymmetry of the triploids to 50 normal diploid fish from the same strains raised in these hatcheries. The triploids have a significantly higher mean proportion of heterozygous loci per individual than normal diploids (Arlee, 0.075 vs. $0.053, P<0.001$; Spokane, $0 \cdot 070$ vs. $0 \cdot 060, P<0 \cdot 001$ ). The observed increase in heterozygosity of the triploids is close to that expected based on gene-centromere recombination rates (Allendorf and Leary, 1984). Triploids from Arlee and Spokane also have a lower average of both measures of fluctuating 
Table 2 Fluctuating asymmetry in diploid and triploid rainbow trout

\begin{tabular}{llccc}
\hline & \multicolumn{2}{c}{ Triploid } & \multicolumn{2}{c}{ Diploid } \\
Strain & Number & Magnitude & Number & Magnitude \\
\hline Arlee & 1.51 & 1.67 & 1.80 & 2.08 \\
Spokane & 1.56 & 1.76 & 1.78 & 1.90 \\
\hline
\end{tabular}

asymmetry than diploids (table 2 ). A lower proportion of triploids are asymmetric for each character in both samples except for gillrakers on the lower first branchial arches in the Spokane sample (sign test, $P<0.05)$.

\section{Total counts of meristic characters}

The first 25 randomly chosen fish from each family in table 1 were combined into two "population" samples to test for differences in total meristic counts (left plus right) for each trait between gynogenetic $(N=109)$ and normal diploids $(N=300)$. Gynogenetic diploids have lower mean meristic counts for four of the five traits (table 3). This difference is significant (Wilcoxon two-sample test, $P<0.05)$ for two characters, pectoral fin rays and mandibular pores. In addition, the gynogenetic diploids also have a significantly greater variance for mandibular pores $(3.52$ vs. $1.84, P<0.001)$.

Table 3 Comparison of meristic counts between gynogenetic and normal diploid rainbow trout

\begin{tabular}{lccccc}
\hline & \multicolumn{3}{c}{$\begin{array}{l}\text { Gynogenetic } \\
\text { Trait }\end{array}$} & \multicolumn{3}{c}{ Normal } \\
& Mean & SD & Mean & SD & $P$ \\
\hline $\begin{array}{l}\text { Pectoral rays } \\
\text { Pelvic rays }\end{array}$ & 27.9 & 1.21 & 28.6 & 1.35 & $<0.001$ \\
$\begin{array}{l}\text { Lower } \\
\text { gillrakers }\end{array}$ & 19.5 & 0.87 & 19.6 & 1.01 & $<0.30$ \\
$\begin{array}{c}\text { Mandibular } \\
\text { pores }\end{array}$ & 15.1 & 1.88 & 15.6 & 1.36 & $<0.02$ \\
$\begin{array}{c}\text { Upper } \\
\text { gillrakers }\end{array}$ & 17.6 & 1.25 & 17.5 & 1.28 & $<0.35$ \\
\hline
\end{tabular}

We also compared the mean meristic counts between triploids and their diploid counterparts (table 4). In contrast to the gynogenetic diploids, there is no consistent pattern of differences. The diploids have a significantly greater number of lower gillrakers in the Arlee strain, and a significantly greater number of mandibular pores but significantly fewer pectoral rays in the Spokane strain. Considering all ten comparisons, diploids have greater mean meristic counts than triploids for six characters, lower for three, and equivalent for one.

\section{DISCUSSION}

\section{Gynogenetic diploids}

Mather (1953) and Thoday (1953) were the first to use the phenotypic similarity of the left and right sides of individuals to measure developmental stability. Phenotypic differences within individuals for bilateral traits exhibiting fluctuating asymmetry reflect the inability of an organism to develop precisely along predetermined pathways. Increased developmental stability is reflected by reduced fluctuating asymmetry. There is empirical evidence supporting the relationship between increased homozygosity and reduced developmental stability, as measured by fluctuating asymmetry (Mather 1953; Thoday 1953; Reeve 1960; Brückner 1976; Leary et al., 1984a, 1985a,b).

The results with gynogenetic diploids are in agreement with Lerner's hypothesis that heterozygosity acts to stabilise development. Gynogenetic diploid progeny are identical by descent at approximately 34 per cent of all loci (Thorgaard et al., 1983; Guyomard, 1984) and have approximately a 50 per cent increase in asymmetry (table 1). This association between reduced heterozygosity and reduced developmental stability results from increased asymmetry at all five characters.

Table 4 Comparison of meristic counts between triploid and diploid rainbow trout

\begin{tabular}{|c|c|c|c|c|c|c|}
\hline \multirow[b]{2}{*}{ Strain } & \multirow[b]{2}{*}{ 'Trait } & \multicolumn{2}{|c|}{ Triploids } & \multicolumn{2}{|c|}{ Diploids } & \multirow[b]{2}{*}{$P$} \\
\hline & & Mean & SD & Mean & SD & \\
\hline \multirow[t]{5}{*}{ Arlee } & Pectoral rays & $29 \cdot 3$ & $2 \cdot 16$ & $28 \cdot 8$ & $1 \cdot 32$ & $<0 \cdot 30$ \\
\hline & Pelvic rays & $19 \cdot 6$ & $1 \cdot 50$ & $19 \cdot 9$ & 0.74 & $<0 \cdot 30$ \\
\hline & Lower gillrakers & $22 \cdot 3$ & $1 \cdot 25$ & $23 \cdot 4$ & $2 \cdot 12$ & $<0.001$ \\
\hline & Mandibular pores & $15 \cdot 4$ & $1 \cdot 47$ & $15 \cdot 9$ & $1 \cdot 37$ & $<0.20$ \\
\hline & Upper gillrakers & $17 \cdot 6$ & $1 \cdot 19$ & $17 \cdot 6$ & $1 \cdot 20$ & $<0.90$ \\
\hline \multirow[t]{5}{*}{ Spokane } & Pectoral rays & $30 \cdot 1$ & $1 \cdot 10$ & $29 \cdot 6$ & $1 \cdot 25$ & $<0 \cdot 05$ \\
\hline & Pelvic rays & $20 \cdot 7$ & $0 \cdot 87$ & $20 \cdot 5$ & $0 \cdot 76$ & $<0.50$ \\
\hline & Lower gillrakers & $23 \cdot 4$ & $1 \cdot 39$ & $23 \cdot 7$ & $1 \cdot 53$ & $<0.50$ \\
\hline & Mandibular pores & $15 \cdot 7$ & $1 \cdot 29$ & $16 \cdot 6$ & $1 \cdot 53$ & $<0.01$ \\
\hline & Upper gillrakers & $18 \cdot 3$ & $1 \cdot 04$ & $18 \cdot 4$ & $1 \cdot 25$ & $<0.90$ \\
\hline
\end{tabular}


The reduced asymmetry found in both groups of triploids indicates that the increased asymmetry in gynogenetic diploids was probably not caused by the post-activation heat shock. The reduced developmental stability of the gynogenetic diploids is also reflected by the significantly greater variance for mandibular pores.

Previous results with a hatchery population of westslope cutthroat trout (Salmo clarki lewisi) that has reduced genetic variability because of a population size bottleneck indicated that increased asymmetry was associated with reduced meristic counts (Leary et al., 1985b). This same relationship is apparent in the gynogenetic diploids (table 3 ). These results, combined with the high heritabilities of these traits in rainbow trout (Leary et al., 1985a), suggest that the increased asymmetry may be due to the failure to produce the genetically programmed number of body parts. Lower meristic counts are generally associated with faster rates of development in rainbow trout (Leary et al., 1984b). However, the gynogenetic diploids develop slower than normal diploids (unpublished data). Koehn and Shumway (1982) have suggested that more heterozygous individuals may be more efficient in producing energy for growth and development. The increased asymmetry, slower development, and lower meristic counts in gynogenetic diploids may all be related to the decreased availability of energy during development.

\section{Triploids}

Both samples of triploids had less fluctuating asymmetry than diploids from the same strains raised in the same hatchery. This is due to a reduction in the proportion of triploid individuals asymmetric for practically every comparison. However, these results do not indicate that triploidy has no deleterious affects on the development of rainbow trout. There may be effects that are not revealed by an examination of asymmetry or that are compensated for by the increased heterozygosity. The relationship between heterozygosity and developmental stability in random mating populations of salmonid fishes (Leary et al., 1984a) suggests that an approximate 30 per cent increase in heterozygosity should have resulted in a much greater decrease in asymmetry than observed. However, it is possible that salmonid fishes cannot completely eliminate the expression of environmental variability in these characters because of biological or physical constraints.

Thorgaard and Gall (1979) found that triploid rainbow trout generally have larger erythrocyte nuclear volumes than diploids. Increased nuclear size is associated with increased cell size in polyploid amphibians and other fishes (Fankhauser, 1945; Swarup, 1959; Beck and Biggers, 1983). Although triploid rainbow trout apparently have larger cells than diploids, they are not larger than diploids (Thorgaard and Gall, 1979), implying that triploids have fewer cells. This is supported by Benfey and Sutterlin (1984) who found that triploid Atlantic salmon (Salmo salar) have larger but fewer erythrocytes, resulting in hematocrits that are nearly identical to those of diploids.

The morphology of the triploids is remarkably similar to that of their diploid counterparts. There is no evidence of consistent differences in meristic counts between diploids and triploids. Changes in developmental rate, however, are known to affect meristic counts in fishes (see Leary et al., (1984b) for discussion of literature). Furthermore, we have found that changes in developmental rate associated with the effects of even a single locus has a large affect on meristic counts in the Arlee strain (Leary et al., 1984b). The similarity in meristic counts between the diploids and the triploids, therefore, suggests that they do not have different developmental rates. Swarup (1959) found no difference in developmental rate between triploid and diploid sticklebacks (Gasterosteus aculeatus) and Fankhauser (1945) reports the same result with amphibians. The similarity between the developmental rate of diploid and triploid fishes implies that developmental rate is not controlled by cell number or the number of cell divisions. This is similar to the developmental programme of starfish (Mita and Obata, 1984), but different from that of the mouse where the timing of certain events is known to depend on total cell number (Lewis and Rossant, 1982). A possible reason for the inability to produce viable polyploid mammals is due to the dependence of the timing of developmental events on cell number. This relationship is further supported by the lack of developmental problems associated with polyploid plants since the timing of developmental events in plants is also not related to the number of cell divisions (G. L. Stebbins, personal communication).

\section{Heterozygosity and developmental stability}

We expected that gynogenetic diploids would have a greater increase in fluctuating asymmetry than observed. This expectation was based on the relationship between asymmetry and heterozygosity present within the narrow range of heterozygosity discriminated using isozymes in random mating 
populations. There are several possible explanations for this discrepancy. Our previous results indicated that heterozygosity at $\operatorname{Sod} 1, M d h 3$, and $M d h 4$ may enhance developmental stability more than heterozygosity at other loci that we examined (Leary et al., 1984a). These loci are on chromosomal segments distal to their centromeres so that there is almost always exactly one crossover between them and their centromeres (Thorgaard et al., 1983). The progeny from females heterozygous for these or other similar loci, therefore, are almost all heterozygotes. Heterozygosity at distal loci or chromosomal segments may in general have a greater effect on developmental stability than at more proximal loci (Leary et al., 1984a). Thus, although gynogenesis has resulted in a 34 per cent mean reduction in genomic heterozygosity, the progeny still tend to be heterozygous for those distal chromosomal segments with large effects on developmental stability.

All of the gynogenetic diploid sib-groups had greater than 50 per cent mortality before they were sampled, and in some families the mortality was greater than 90 per cent. The discrepancy between our expectations and observations might result from decreased survival of individuals with greater asymmetry. Thus, the gynogenetic diploids would have had a greater increase in asymmetry if they were analysed at a younger age. Most deaths occurred very early in development before the fish were large enough for meristic analysis. However, the unusually late mortalities in family $\mathrm{J} 11$ allow us to test this hypothesis in one sib-group. The significantly greater magnitude of asymmetry of the mortalities and the negative correlation between time of death and asymmetry suggests that selective mortality may have played a role in reducing the asymmetry of gynogenetic diploids.

We have previously found a relationship between the presence of obvious morphological deformities and greatly increased fluctuating asymmetry (Leary et al., 1984a). This and the apparent relationship between survival and lower asymmetry in gynogenetic diploids suggest that fluctuating asymmetry is a good indicator of general developmental buffering capacity and is closely associated with fitness. The absence of detectable additive genetic variation for fluctuating asymmetry suggests that it has been under constant directional selection (Leary et al., 1985a).

The range of the mean number of asymmetric traits per individual in salmonid populations is surprisingly narrow. It ranges between 1.30 and 1.90 in 24 hatchery and natural populations of 8 species that we have examined (Leary et al., 1984a, unpublished data). The only exception to this is the high asymmetries in fish with reduced heterozygosity or obvious morphological deformities (this paper, Leary et al., 1984b, 1985a). We suggest that the narrow range of asymmetry in populations results from an upper limit restricted by constant directional selection for developmental stability and a lower limit determined by the amount of randomness or "developmental noise" inherent in the developmental process.

Acknowledgments This work was supported by National Science Foundation grants ISP-8011449 and BSR-8300039 to FWA and PCM-8108787 to GHT. We would like to thank Jim Crepeau, Jack Boyce, and Mike Albert for providing the fish used in this study. Appreciation is also extended to the Montana Department of Fish, Wildlife and Parks for their continued support, Paul Scheerer for technical assitance and H. McPherson for stimulating conversation. This paper was written while RFL. and FWA were visitors at the Department of Genetics, University of California, Davis; we thank Francisco Ayala for his hospitality.

\section{REFERENCES}

ALLINIOORF, F. W. AND LEARY, R. F. 1984. Heterozygosity in gynogenetic diploids and triploids estimated by genecentromere recombination rates. Aquaculture, 42, in press.

BECK, M. L. ANI) BIGGI:RS, I. 1983. Erythrocyte measurements of diploid and triploid Ctenopharyngodon idella $\times$ Hypophthalmichthys nobilis hybrids. J. Fish. Biol., 22, 497502

BENFEY, T. J. ANI) SUTTERIIN. A. M. 1984. The haematology of triploid landlocked Atlantic salmon, Salmo salar L. $J$. Fish. Biol, 24, 333-338.

BRIJCKNER, D. 1976. The influence of genetic variability on wing asymmetry in honeybees (Apis mellifera). Evol., 30, $100-108$

CHAKRABORTY, R. 1981. The distribution of the number of heterozygous loci in an individual in natural populations. Genetics, 98, 461-466.

FANKHAUSER, G. 1945. The effects of changes in chromosome number on amphibian development. Quart. Rev. Biol., 20, $20-78$.

(iUYOMARI), R. 1984. High level of residual heterozygosity in gynogenetic rainbow trout, Salmo gairdneri, Richardson. Theor. Appl. Genet., 67, 307-316.

KOEHN, R. K. ANI) SHUMWAY, S. F. 1982. A genetic/physiological explanation for diflerential growth rate among individuals of the American oyster, Crassostrea virginica (Gmelin). Marine Biol. Letters, 3, 35-42.

I.FARY, R. F., ALLENIDORF, I. W. AND KNUDSEN, K. L. 1983. Developmental stability and enzyme heterozygosity in rainbow trout. Nature, 301, 71-72.

I.EARY, R. F., ALLENIDORF, F. W. ANI KNUIDSEN, K. I.. $1984 a$ Superior developmental stability of heterozygotes at enzyme loci in salmonid fishes. Amer. Natur., 124, 540-551.

I.FARY, R. F. ALLENDORF, F. W. ANI) KNUIDSF, K. L. $1984 b$ Major morphological effects of a regulatory gene: Pgml-t in rainbow trout. Molec. Biol. Evol, 1, 183-194.

LEARY, R. F, ALIIINI) ORF, F. W. AND KNUDSEN, K. L. $1985 a$. Inheritance of meristic variation and the evolution of developmental stability in rainbow trout. Evol., 38 , in press. 
LEARY, R. F., ALIFNDORF, F. W. AND KNUDSEN, K. L. $1985 b$. Developmental instability as an indicator of the loss of genetic variation in hatchery trout. Trans. Amer. Fish. Soc., $114,222-227$.

LERNER, 1. M. 1954. Genetic homeostasis. Wiley, New York. LEWIS, N. E. AND ROSSANT, J. 1982. Mechanism of size regulation in mouse embryo aggregates. J. Embryol. Exp. Morphol., 72, 169-181.

MATHER, K. 1953. Genetical control of stability in development. Heredity, 7, 297-336.

MITA, I. ANI) OBATA, C. 1984. Timing of early morphogenetic events in tetraploid starfish embryos. J. Exper. Zool., 229, 215-222.

PURDOM, C. F. 1983. Genetic engineering by the manipulation of chromosomes. Aquaculture, 33, 287-300.

REEVE, F. C: R. 1960. Some genetic tests on asymmetry of sternopleural chaeta in Drosophila. Genet. Res., I, 151-172.

SCHEERER, P. D. AND THORGAARD, G. H. 1983. Increased survival in salmonid hybrids by induced triploidy. Canad. J. Fish. Aquatic Sci., 40, 2040-2044.

SWARUP, H. 1959. Effect of triploidy on the body size, general organization and cellular structure in Gasterosteus aculeatus (L.). J. Genet., 56, 143-155.
THORGAARD, G. H. 1983. Chromosome set manipulation and sex control in fish. In Fish Physiology 9B, 405-434. Academic Press.

THORGAARD, G., ALLENDORF, F. W. AND KNUDSEN, K. L. 1983. Gene-centromere mapping in rainbow trout: high interference over long map distances. Genetics, 103, 771783.

THORGAARI, G. H. AND GALL, G. A. E. 1979. Adult triploids in a rainbow trout family. Genetics, 93, 961-973.

THORGAARD, G. H., JAZWIN, M. E. ANI STIER, A. R. 1981. Polyploidy induced by heat shock in rainbow trout. Trans. Amer. Fish. Soc., 110, 546-550.

THOI)AY, J. M. 1953. Components of fitness. Symp. Soc. Exper. Biol., 7, 96-113.

VAN VALEN, L. 1962. A study of fluctuating asymmetry. Evol., $16,125-142$.

WADDINGTON, C. H. 1942. Canalization of development and the inheritance of acquired characters. Nature, 150, 563565 .

WADDINGTON, C. H. 1948. Polygenes and oligogenes. Nature, $151,395$. 